\title{
Outcomes of Modified Canal Wall Down Mastoidectomy and Mastoid Obliteration Using Autologous Materials
}

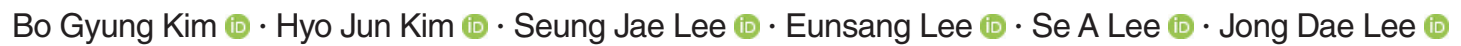 \\ Department of Otorhinolaryngology-Head and Neck Surgery, Soonchunhyang University College of Medicine, Bucheon, Korea
}

Objectives. The traditional canal wall down mastoidectomy (CWDM) procedure commonly has potential problems of altering the anatomy and physiology of the middle ear and mastoid. This study evaluated outcomes in patients who underwent modified canal wall down mastoidectomy (mCWDM) and mastoid obliteration using autologous materials.

Methods. Our study included 76 patients with chronic otitis media, cholesteatoma, and adhesive otitis who underwent mCWDM and mastoid obliteration using autologous materials between 2010 and 2015. Postoperative hearing airbone gap and complications were evaluated.

Results. During the average follow-up of 64 months (range, 20 to 89 months), there was no recurrent or residual cholesteatoma or chronic otitis media. No patient had a cavity problem and anatomic integrity of the posterior canal wall was obtained. There was a significant improvement in hearing with respect to the postoperative air-bone gap $(P<0.05)$. A retroauricular skin depression was a common complication of this technique.

Conclusion. The present study suggests that our technique can prevent various complications of the classical CWDM technique using autologous tissues for mastoid cavity obliteration. It is also an appropriate method to obtain adequate volume for safe obliteration.

Keywords. Mastoidectomy; Mastoid; Cartilage; Bone

\section{INTRODUCTION}

The goals of mastoidectomy surgery are firstly to eradicate disease and secondly to reconstruct the normal anatomy of the middle ear. Canal wall down mastoidectomy $(\mathrm{CWDM})$ procedures have advantages over canal wall up mastoidectomy (CWUM) procedures in that a residual cholesteatoma can be found easily in a follow-up evaluation and recurrent disease occurs at a lower rate [1-3]. Meatoplasty is an essential part of the

\footnotetext{
- Received September 19, 2018

Revised November 16, 2018

Accepted December 7, 2018

- Corresponding author: Jong Dae Lee

Department of Otorhinolaryngology-Head and Neck Surgery,

Soonchunhyang University Bucheon Hospital, Soonchunhyang University

College of Medicine, 170 Jomaru-ro, Wonmi-gu, Bucheon 14584, Korea

Tel: +82-32-621-6951, Fax: +82-32-621-5018

E-mail: ljdent@schmc.ac.kr
}

traditional CWDM. However, traditional CWDM procedures combined with meatoplasty have a common problem of potentially altering the anatomy and physiology of the middle ear and mastoid leading to frequent mastoid cavity problems such as a draining ear followed by the accumulation of keratin debris [4]. Moreover, this procedure also can result in difficulty fitting a hearing aid, vertigo attacks following temperature or pressure changes, and alteration of the position of the pinna $[5,6]$.

The retraction pocket is due to the negative pressure produced from the preserved air-filled mastoid cavity [7]. A retraction pocket results from a poorly functioning eustachian tube and leads to erosion of the scutum and formation of a cholesteatoma. Several surgical methods have been reported to prevent the occurrence of retraction pockets [8,9]. Mastoid and epitympanic obliteration is performed to minimize the dead space in the mastoid cavity and obliterate the epitympanic space. Several materials have been suggested for mastoid and epitympanic

Copyright @ 2019 by Korean Society of Otorhinolaryngology-Head and Neck Surgery.

This is an open-access article distributed under the terms of the Creative Commons Attribution Non-Commercial License (http://creativecommons.org/licenses/by-nc/4.0)

which permits unrestricted non-commercial use, distribution, and reproduction in any medium, provided the original work is properly cited. 
obliteration such as a pedicled flap [10,11], fat [12], cartilage [13, $14]$, bone pate $[12,15]$, homogenous bone chips [11], and hydroxyapatite $[13,16]$.

The authors designed a new technique to avoid problems resulting from meatoplasty and to prevent a retraction pocket. The connection between the mastoid cavity and the middle ear was blocked by obliterating the epitympanum with concha cartilage. Bone pate was used to smooth the mastoid bowl and the remaining mastoid cavity was obliterated by an extended inferior based flap (IBF). The present study investigated the outcomes of patients who underwent modified canal wall down mastoidectomy (mCWDM) and mastoid obliteration using autologous materials.

\section{MATERIALS AND METHODS}

\section{Ethical considerations}

The authors had no ethical concerns in performing this retrospective study. This study was approved by the Institutional Review Board of Soonchunhyang University (IRB No. 2018-04-017) and informed consent was waived.

\section{Subjects}

Between January 2010 and December 2015, 76 patients who underwent $\mathrm{mCWDM}$ and mastoid obliteration using autologous materials were considered for enrollment. We included patients with (1) chronic otitis media $(n=22),(2)$ cholesteatoma $(n=30)$, and (3) adhesive otitis $(n=24)$. All patients had a sclerotic mastoid diagnosed by temporal bone computed tomography. Moreover mCWDM and mastoid obliteration using autologous materials were performed by a single surgeon (JDL). We excluded patients who underwent revision surgery.

\section{Surgical techniques}

Under general anesthesia, a conventional retroauricular incision was made $0.5-1 \mathrm{~cm}$ posterior to the attachment of the auricle. With electrocautery, the cut was advanced anteriorly to-

\section{H I I G H L L I}

- The traditional canal wall down mastoidectomy with meatoplasty procedure commonly has potential problems of altering the anatomy and physiology of the middle ear and mastoid.

- Modified canal wall down mastoidectomy and mastoid obliteration using autologous materials without meatoplasty has no cavity problem.

- Modified canal wall down mastoidectomy and mastoid obliteration significantly improves in hearing with respect to the postoperative air-bone gap.

- This surgical technique can prevent various complications of the classical canal wall down mastoidectomy technique using autologous tissues for mastoid cavity obliteration. ward the external auditory canal while preserving connective tissue layers. The temporalis muscle area was exposed widely and the temporalis muscle fascia was harvested. An extended IBF including the temporalis muscle was designed and elevated. Healthy cortical bone pate from only the temporal area was collected in a glass bottle by using a cutting bur. It was then mixed with a povidone-iodine solution and dried. A retrograde (inside out) mastoidectomy was performed to drill out all air cells with preservation of the posterior external auditory canal skin flap. Pathologic lesions such as a cholesteatoma, retraction pocket, and eroded ossicles were removed. The antrum and epitympanic space superior to the tympanic segment of the facial nerve were obliterated with crushed cartilage. The cartilage was harvested from concha cartilage and crushed in a cartilage crusher by Cottle mallet. Fibrin sealant (Baxter AG, Vienna, Austria) was used to support the crushed cartilage and prevent it from falling into the middle ear. All mastoid recesses and the cavity itself were filled with bone pate, which was smoothed and flattened on the bowlike mastoid. The remaining mastoid cavity was obliterated with an extended IBF. A temporalis muscle fascia graft was placed on the IBF and reconstruction of the tympanic membrane was performed. The surgical procedure is shown in Fig. 1.

The tympanic membrane and mastoid cavity were examined initially 2 weeks after surgery using a surgical microscope. The patients had 1-month follow-up visit, 3-month interval followup visit, and 6-month interval follow-up visits thereafter.

\section{Postoperative outcomes}

The follow-up duration after surgery averaged 64 months and ranged from 20 to 89 months. One staged ossicular reconstruction was performed for hearing gain for all patients during the CWDM. A type T3 tympanoplasty (the columella over the stapes head) with concha cartilage was performed for 56 patients, a type T4 tympanoplasty (the columella over the footplate) with concha cartilage was performed for 15 patients, and a type T0 tympanoplasty (tympanization) was performed for five patients.

Hearing outcomes were evaluated by comparing pre- and postoperative air-bone gaps 12 months after surgery. The hearing outcome was evaluated by the average hearing thresholds at four frequencies $(500,1,000,2,000$, and 3,000 Hz) according to the 1995 American Academy of Otolaryngology-Head and Neck Surgery guidelines [17]. Postoperative complications after mCWDM and mastoid obliteration using autologous materials were also investigated.

\section{Statistical analysis}

For the statistical analysis, we used Origin 8 software (OriginLab, Northampton, MA, USA). The average air-bone gap values before and after the staged operation were evaluated using the two-tailed Student $t$-test. Differences in postoperative air-bone gap values among patients with chronic otitis media, cholestea- 
toma, and adhesive otitis were evaluated using a one-way analysis of variance. The Pearson correlation was used to assess correlations between the postoperative air-bone gap and each disease. A $P<0.05$ was considered statistically significant.

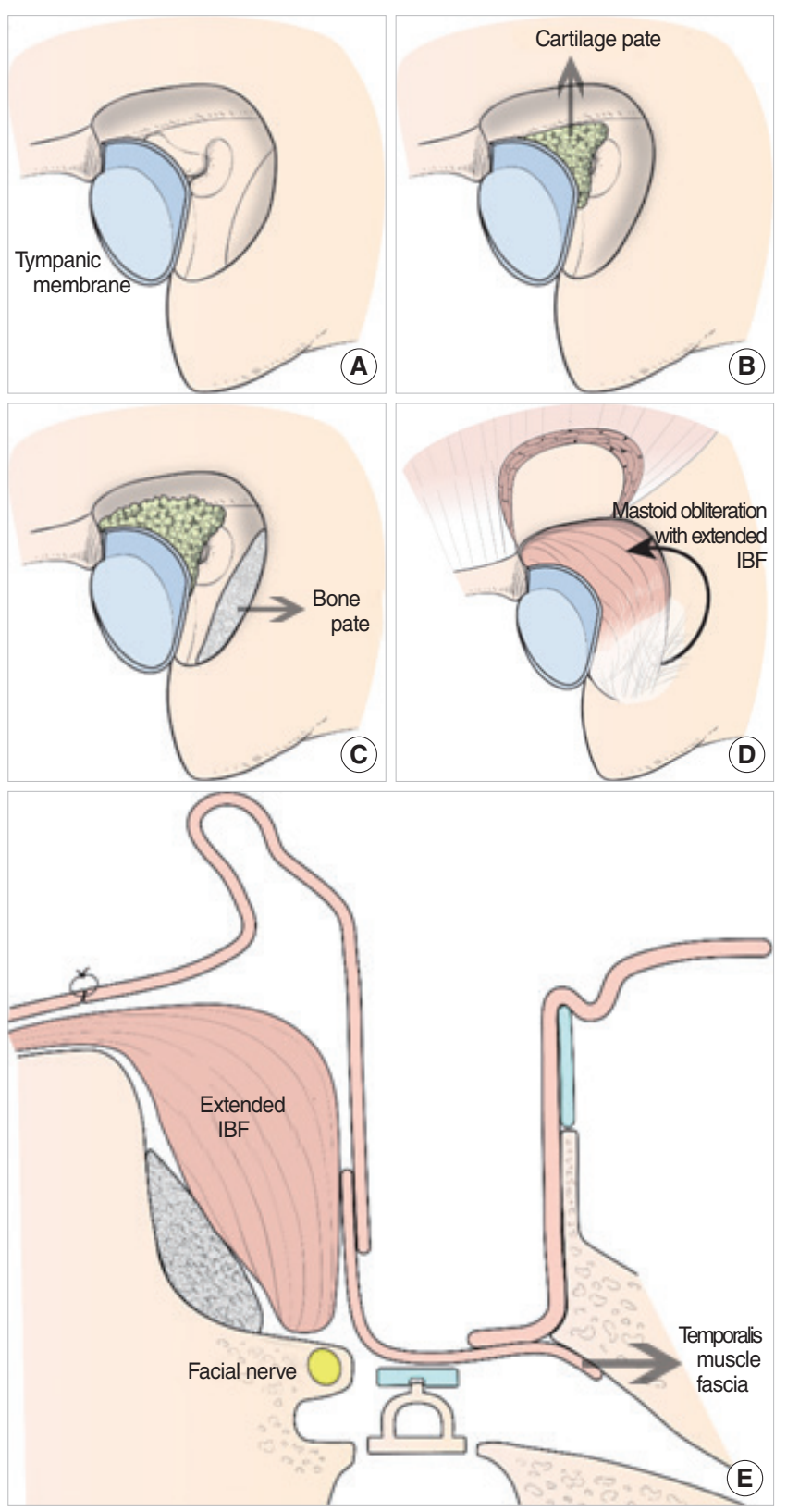

Fig. 1. Schematic drawings of the procedure: modified canal wall down mastoidectomy and mastoid obliteration using autologous materials. (A) A complete mastoidectomy is performed. (B) The antrum and epitympanic space superior to the tympanic segment of the facial nerve are obliterated with crushed cartilage harvested from concha cartilage. (C) Bone pate is used to smooth the mastoid bowl. (D) The remaining mastoid cavity is obliterated with an extended inferior based flap (IBF). (E) A temporalis muscle fascia graft is placed on the IBF and reconstruction of the tympanic membrane is performed.

\section{RESULTS}

Seventy-six patients (29 male and 47 female patients) who underwent mCWDM and mastoid obliteration using autologous materials were included in this study. The mean age at which the patients underwent surgery was $49.9 \pm 10.9$ years. The characteristics of the patients are summarized in Table 1.

\section{Hearing results}

Of all 76 patients who underwent one staged operation and pure tone audiometry at the 12-month follow-up, 11 (14.5\%) showed a postoperative air-bone gap value of 0-10 $\mathrm{dB}$ hearing level (HL) and 28 (36.8\%) showed a postoperative air-bone gap value of 10-20 dB HL. A postoperative air-bone gap value of 20-30 dB HL was observed in 23 patients $(30.3 \%)$ and a value $>30 \mathrm{~dB}$ HL was observed in 14 patients (18.4\%). Hearing results at 12 months after the surgery are shown in Table 2.

The average air-bone gap values were $26.7 \pm 10.9 \mathrm{~dB}$ HL before the operation and $20.8 \pm 10.8 \mathrm{~dB} \mathrm{HL}$ after the operation $(P=0.001)$. Postoperative hearing outcomes improved significantly after the operation. Postoperative air-bone gap values, according to disease patterns, are shown in Fig. 2. The postoperative air-bone gap value differed significantly among patients with chronic otitis media, cholesteatoma, and adhesive otitis ( $P=$ 0.029). Postoperative air-bone gap values differed significantly between patients with chronic otitis media and cholesteatoma $(P=0.025)$. Postoperative air-bone gap values did not differ significantly between patients with chronic otitis media and adhesive otitis, or between patients with cholesteatoma and adhesive otitis ( $P=0.363$ and $P=0.803$, respectively).

Table 1. Demographics of the patients

\begin{tabular}{lc}
\hline Variable & Value \\
\hline Male:female & $29: 47$ \\
Age (yr) & $49.9 \pm 10.9$ \\
Follow-up duration (mo) & $64(20-89)$ \\
Disease pattern & 76 \\
Chronic otitis media & $22(28.9)$ \\
Cholesteatoma & $30(39.5)$ \\
Adhesive otitis & $24(31.6)$ \\
\hline
\end{tabular}

Values are presented as mean \pm standard deviation, median (range), or number (\%).

Table 2. Postoperative hearing outcomes at 12 months after surgery

\begin{tabular}{lc}
\hline Postoperative air-bone gap & No. of cases (\%) \\
\hline $0-10 \mathrm{~dB} \mathrm{HL}$ & $11(14.5)$ \\
$10-20 \mathrm{~dB} \mathrm{HL}$ & $28(36.8)$ \\
$20-30 \mathrm{~dB} \mathrm{HL}$ & $23(30.3)$ \\
$>30 \mathrm{~dB} \mathrm{HL}$ & $14(18.4)$ \\
Total & $76(100)$ \\
\hline
\end{tabular}

$\mathrm{HL}$, hearing level. 


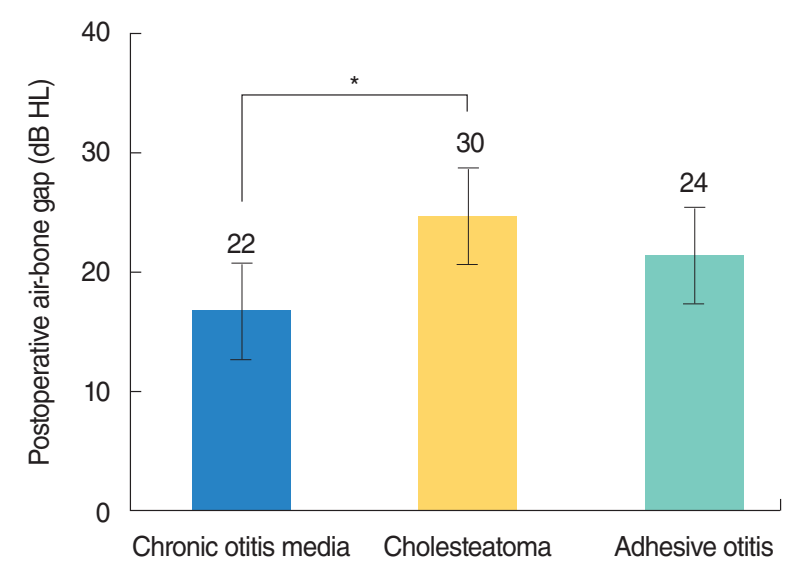

Fig. 2. The postoperative air-bone gap values among patients with various disease patterns. The number above each bar represents the number of patients. $\mathrm{HL}$, hearing level. ${ }^{\star} P<0.05$.

\section{Restoration of anatomy}

All patients showed restored external auditory canal anatomy after $\mathrm{mCWDM}$ and mastoid obliteration using autologous materials. No patient complained of any problem such as ear discharge followed by an accumulation of keratin debris or dizziness according to temperature or pressure changes.

We present two representative cases that underwent mCWDM and mastoid obliteration using autologous materials. Fig. 3 shows the pre- and postoperative findings (Supplementary Material 1, Video clip 1) of a patient with chronic otitis media and Fig. 4 and Supplementary Material 2 (Video clip 2) shows the case of a patient with a cholesteatoma. The hearing outcomes and external auditory canal restorations were favorable.

\section{Surgical complications}

Two of 76 patients $(2.6 \%)$ experienced dry drum perforations
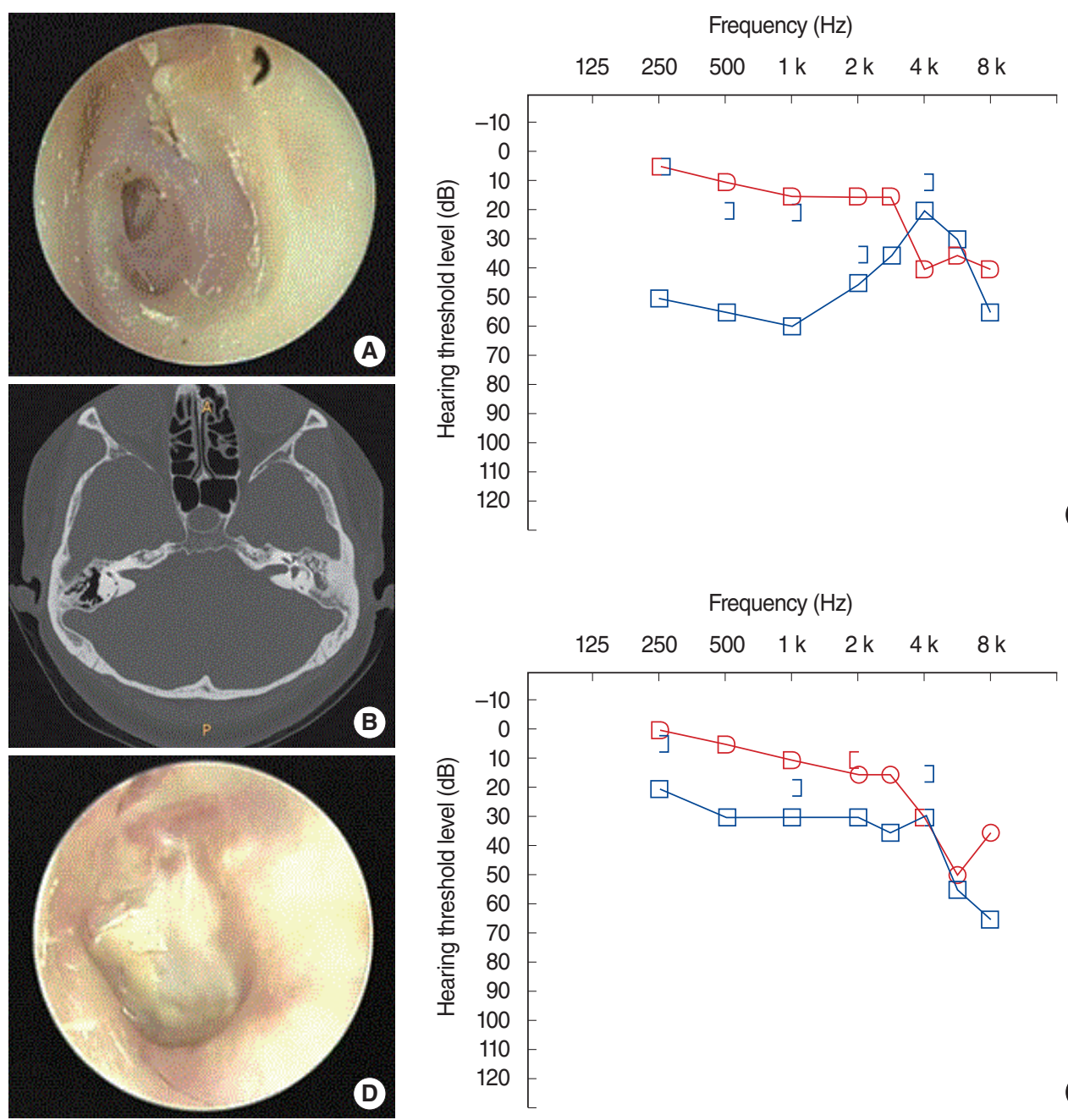

Fig. 3. Pre- and postoperative findings in a patient with chronic otitis media in the left ear. (A) A preoperative finding of a perforated left anterior drum. (B) A computed tomography scan obtained before surgery shows chronic otitis media in the left ear (blue lines; right ear, red lines). (C) Preoperative audiometry shows an air-bone gap in the left ear. (D) One-year postoperative external auditory canal findings after posterior wall reconstruction and mastoid obliteration. (E) One-year postoperative audiometry shows improvement in the air-bone gap in the left ear. 

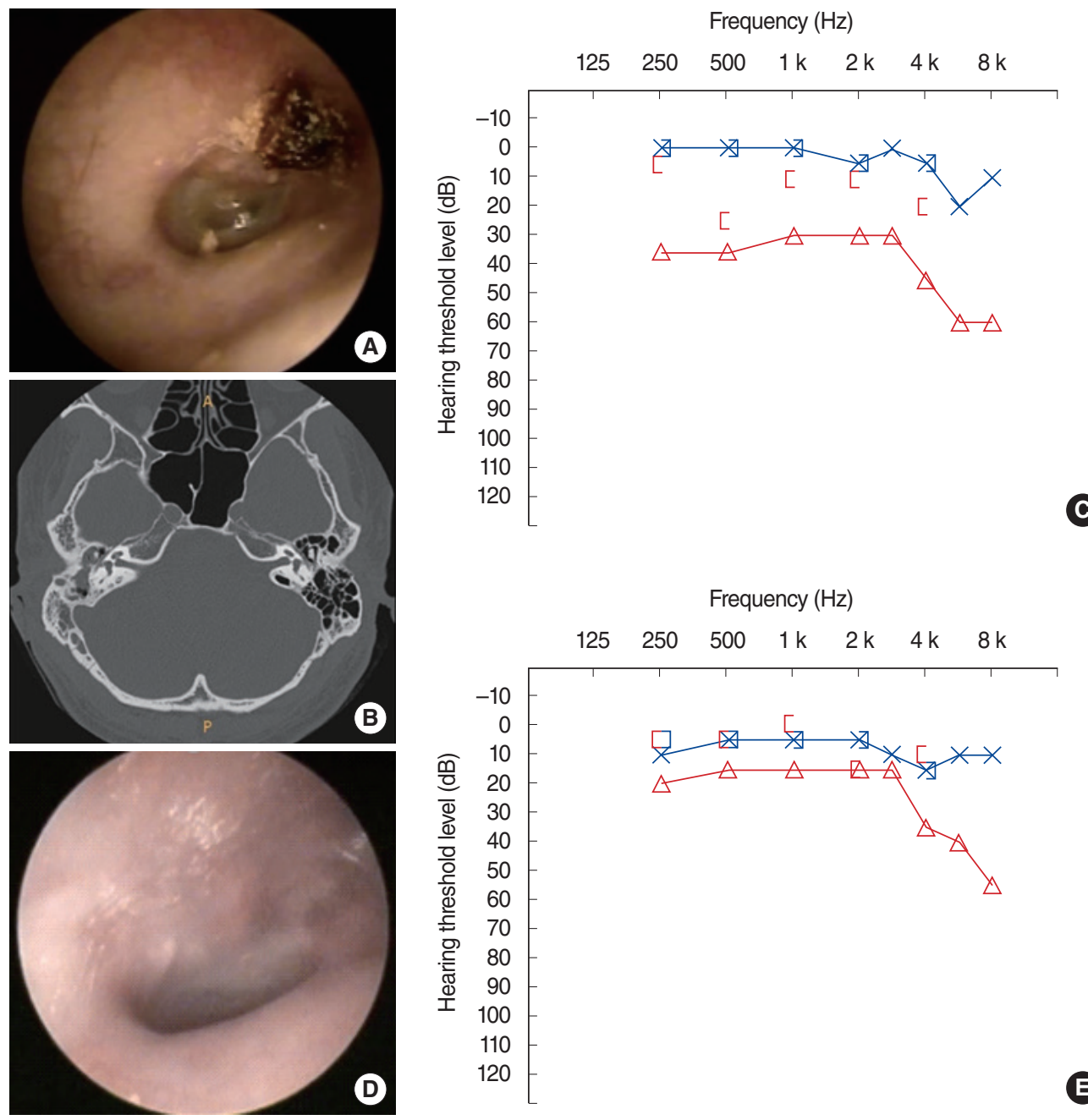

Fig. 4. Pre- and postoperative findings in a patient with a cholesteatoma in the right ear. (A) A preoperative finding of attic destruction in the right ear. (B) A computed tomography scan obtained before surgery shows a cholesteatoma in the right ear. (C) Preoperative audiometry shows an air-bone gap in the right ear (red lines; left ear, blue lines). (D) The external auditory canal is well maintained postoperatively, 1 year after posterior wall reconstruction and mastoid obliteration. (E) One-year postoperative audiometry shows an improvement in the air-bone gap in the right ear.

Table 3. Postoperative complications of mCWDM and mastoid obliteration using autologous materials

\begin{tabular}{lc}
\hline Complication & Case $(n=76)$ \\
\hline Recurrence & 0 \\
Cavity problem & 0 \\
Bone pate infection & 0 \\
Dry TM perforation & $2(2.6)$ \\
Myringitis & $2(2.6)$ \\
\hline
\end{tabular}

Values are presented as number (\%).

mCWDM, modified canal wall down mastoidectomy; TM, tympanic membrane.

and another two patients (2.6\%) developed myringitis and were administered antibiotic eardrops. There was no recurrence of infection, cholesteatoma or adhesion. The external auditory canal was well maintained in all patients and no patient experienced a cavity problem; moreover, there was no bone pate infection.
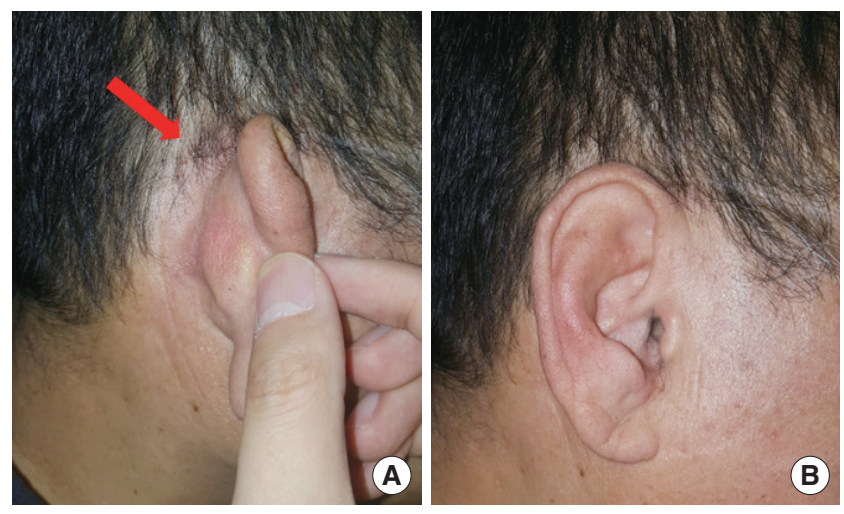

Fig. 5. A retroauricular skin depression is commonly observed in patients after modified canal wall down mastoidectomy and mastoid obliteration using autologous materials. The retroauricular skin depression (arrow, A) was minor, which presented no cosmetic problem (B). 
Surgical complications are described in Table 3. A retroauricular skin depression was very common in patients who underwent $\mathrm{mCWDM}$ and mastoid obliteration using autologous materials (Fig. 5). However, the posterior ear canal was well maintained and the retroauricular skin depression was minor, which presented no functional or cosmetic problem.

\section{DISCUSSION}

The patients who undergo a traditional CWDM with meatoplasty suffer from cavity problems such as an intermittently draining ear followed by the accumulation of keratin debris, frequent vertigo attacks following temperature or pressure changes, and difficulty fitting a hearing aid $[5,10]$. Our surgical techniques for mCWDM and mastoid obliteration using autologous materials overcome these problems by mastoid obliteration with autologous crushed cartilage and bone pate and convey the advantages of CWDM, which eradicates the disease. Many studies suggested that posterior wall reconstruction with several materials could avoid cavity problems following CWDM [12,18-20]. However, posterior wall reconstruction is not often maintained because of absorption and defects in the reconstructed posterior wall, which finally leads to a retraction pocket [21]. Ikeda et al. [22] reported that out of 103 patients with a cholesteatoma who underwent posterior wall reconstruction, six patients showed retraction of the reconstructed posterior wall within 2 years. Our surgical techniques avoid cavity problems by only mastoid obliteration with an extended IBF and by using autologous crushed cartilage and bone pate to make a smooth mastoid bowl. Moreover, no patient demonstrated a mastoid cavity problem among all 76 patients.

One of the merits of our surgical technique using autologous crushed cartilage and bone pate is a lower risk of infection. The concha cartilage was harvested and used to block the connection between the mastoid cavity and middle ear by obliterating the epitympanum. Bone pate was only collected from healthy cortical bone underneath the temporalis muscle after elevation of the IBF. We have used autologous bone pate for mastoid obliteration to make a smoothly contoured cavity after eradicating the disease. Grafted autologous bone pate was reported to be transformed into new bone and contributed to the maintenance of volume without inflammation $[19,23]$. Additionally, autologous bone pate is known to be more biocompatible than artificial materials [24]. Artificial materials such as hydroxyapatite, silicone, and synthetic bone were reported to be used for mastoid obliteration, but are relatively expensive and often lead to integration failure and infection [25].

The primary goal of tympanomastoidectomy is to eliminate the disease and restore the anatomy. However, hearing reconstruction is an important secondary factor. The hearing outcomes of our surgical technique were satisfactory even though only one staged operation was performed. Of the 76 patients who underwent one staged operation, 39 (51.3\%) demonstrated a postoperative air-bone gap less than $20 \mathrm{~dB}$ HL. We performed a second staged operation in patients with an air-bone gap greater than $20 \mathrm{~dB}$ HL when postoperative temporal bone computed tomography showed a well-healed and aerated middle ear (data not shown). A second staged operation was performed at 1 year after $\mathrm{mCWDM}$ and mastoid obliteration using autologous materials. Gantz et al. [11] reported the surgical outcomes of removing and replacing the posterior canal wall and mastoid obliteration with bone pate in patients with chronic otitis media with a cholesteatoma. Among all 80 patients who underwent surgery, 22 patients $(50 \%)$ had a postoperative air-bone gap less than 20 $\mathrm{dB}$ HL. Lee et al. [12] reported that 151 patients with a cholesteatoma underwent a mastoid and epitympanic obliteration technique and then 56 cases were able to undergo a staged operation to regain hearing. Finally, 37 patients $(24.5 \%)$ demonstrated a postoperative air-bone gap less than $20 \mathrm{~dB} \mathrm{HL}$.

The present study shows that no patient had recurrent chronic otitis media, cholesteatoma, or adhesive otitis. Recurrent disease after CWUM results most commonly from the redevelopment of retraction pockets, which might be caused by continuing poor eustachian tube function. CWDM can visualize the entire middle ear, sinus tympani, mastoid cavity, and whole epitympanum. Removing the head of the malleus and cog allows for inspection of the anterior epitympanum. This helps to complete disease elimination with lower rates of recurrence. The mCWDM and mastoid obliteration using autologous materials resulted in no recurrence complication, cavity problem, or bone pate infection.

A limitation of the present study is that the follow-up duration was approximately 5 years, and more long-term follow-up results would be more convincing. Retraction pockets are known to develop after long-term follow-up periods and lead to recurrent cholesteatoma [3,26,27]. Additionally, another limitation of this technique is the possibility of a hidden cholesteatoma within the obliterated epitympanum and antrum. The differentiation of a cholesteatoma from postoperative changes such as granulation is not easy on temporal bone computed tomography. Magnetic resonance imaging (MRI) is a reliable modality to detect a cholesteatoma within the obliterated mastoid cavity. Aarts et al. [28] reported that the sensitivity, specificity, positive predictive value, and negative predictive value of cholesteatoma detection by three non-echo-planar diffusion-weighted MRI scans were all $97 \%$. Long-term outcomes and follow-up imaging studies of patients who underwent $\mathrm{mCWDM}$ and mastoid obliteration using autologous materials should be investigated further.

In conclusion, we suggest that $\mathrm{mCWDM}$ and mastoid obliteration using autologous materials eradicates disease in the middle ear and epitympanum by direct visualization and prevents common complications of the traditional CWDM technique. Our surgical technique is an appropriate method to obtain adequate volume for mastoid obliteration with autologous bone and cartilage safely and cost-effectively. 


\section{CONFLICT OF INTEREST}

No potential conflict of interest relevant to this article was reported.

\section{ACKNOWLEDGMENTS}

This work was supported by the Soonchunhyang University Research Fund.

The authors would like to thank Dong-Su Jang, B.A. (Research Assistant, Department of Anatomy, Yonsei, University College of Medicine, Seoul, Korea), for his help with the figures.

\section{ORCID}

Bo Gyung Kim https://orcid.org/0000-0002-6203-4754

Hyo Jun Kim https://orcid.org/0000-0002-3921-110X

Seung Jae Lee https://orcid.org/0000-0002-0390-8415

Eunsang Lee https://orcid.org/0000-0002-3582-1138

SeA Lee https://orcid.org/0000-0002-6263-1903

Jong Dae Lee https://orcid.org/0000-0003-2866-9841

\section{AUTHOR CONTRIBUTIONS}

Conceptualization: JDL. Data curation: BGK, HJK. Formal analysis: BGK, SJL, EL. Funding acquisition: BGK, JDL. Methodology: SAL, JDL. Project administration: BGK, JDL. Visualization: JDL. Writing - original draft: BGK. Writing - review \& editing: BGK, JDL.

\section{SUPPLEMENTARY MATERIALS}

Supplementary materials can be found via https://doi.org/10. 21053/ceo.2018.01333.

\section{REFERENCES}

1. Karmarkar S, Bhatia S, Saleh E, DeDonato G, Taibah A, Russo A, et al. Cholesteatoma surgery: the individualized technique. Ann Otol Rhinol Laryngol. 1995 Aug;104(8):591-5.

2. Charachon R, Gratacap B, Tixier C. Closed versus obliteration technique in cholesteatoma surgery. Am J Otol. 1988 Jul;9(4):286-92.

3. Brown JS. A ten year statistical follow-up of 1142 consecutive cases of cholesteatoma: the closed vs. the open technique. Laryngoscope. 1982 Apr;92(4):390-6.

4. Palmgren O. Long-term results of open cavity and tympanomastoid surgery of the chronic ear. Acta Otolaryngol. 1979;88(5-6):343-9.

5. Sade J, Weinberg J, Berco E, Brown M, Halevy A.The marsupialized (radical) mastoid. J Laryngol Otol. 1982 Oct;96(10):869-75.

6. Smyth GD. Canal wall for cholesteatoma: up or down? Long-term results. Am J Otol. 1985 Jan;6(1):1-2.

7. Palva T, Virtanen H. Ear surgery and mastoid air cell system. Arch Otolaryngol. 1981 Feb;107(2):71-3.

8. Lopez Villarejo P, Cantillo Banos E, Ramos J. The antrum exclusion technique in cholesteatoma surgery. J Laryngol Otol. 1992 Feb;106 (2):120-3.

9. Yanagihara N, Gyo K, SasakiY, Hinohira Y. Prevention of recurrence of cholesteatoma in intact canal wall tympanoplasty. Am J Otol. 1993 Nov;14(6):590-4.

10. Palva T. Operative technique in mastoid obliteration. Acta Otolaryngol. 1973 Apr;75(4):289-90.

11. Gantz BJ,Wilkinson EP, Hansen MR. Canal wall reconstruction tympanomastoidectomy with mastoid obliteration. Laryngoscope. 2005 Oct;115(10):1734-40.

12. LeeWS, Choi JY, Song MH, Son EJ, Jung SH, Kim SH. Mastoid and epitympanic obliteration in canal wall up mastoidectomy for prevention of retraction pocket. Otol Neurotol. 2005 Nov;26(6):1107-11.

13. Black B. Mastoidectomy elimination: obliterate, reconstruct, or ablate? Am J Otol. 1998 Sep;19(5):551-7.

14. Dornhoffer JL. Surgical modification of the difficult mastoid cavity. Otolaryngol Head Neck Surg. 1999 Mar;120(3):361-7.

15. Roche P, Coolahan I, Glynn F, Mc Conn WR. Autologous bone pate in middle ear and mastoid reconstruction. Rev Laryngol Otol Rhinol (Bord). 2011;132(4-5):193-6.

16. Grote JJ. Results of cavity reconstruction with hydroxyapatite implants after 15 years. Am J Otol. 1998 Sep;19(5):565-8.

17. Committee on Hearing and Equilibrium guidelines for the evaluation of results of treatment of conductive hearing loss. Otolaryngol Head Neck Surg. 1995 Sep;113(3):186-7.

18. Moffat DA, Gray RF, Irving RM. Mastoid obliteration using bone pate. Clin Otolaryngol Allied Sci. 1994 Apr;19(2):149-57.

19. Roberson JB Jr, Mason TP, Stidham KR. Mastoid obliteration: autogenous cranial bone pAte reconstruction. Otol Neurotol. 2003 Mar; 24(2):132-40.

20. LeeWS, Kim SH, LeeWS, Kim SH, Moon IS, Byeon HK. Canal wall reconstruction and mastoid obliteration in canal wall down tympanomastoidectomized patients. Acta Otolaryngol. 2009 Sep;129(9): 955-61.

21. Wiet RJ, Harvey SA, Pyle MG. Canal wall reconstruction: a newer implantation technique. Laryngoscope. 1993 Jun;103(6):594-9.

22. Ikeda M, Yoshida S, Ikui A, Shigihara S. Canal wall down tympanoplasty with canal reconstruction for middle-ear cholesteatoma: postoperative hearing, cholesteatoma recurrence, and status of re-aeration of reconstructed middle-ear cavity. J Laryngol Otol. 2003 Apr; 117(4):249-55.

23. Linthicum FH Jr. The fate of mastoid obliteration tissue: a histopathological study. Laryngoscope. 2002 Oct;112(10):1777-81.

24. Minatogawa T, Machizuka H, Kumoi T. Evaluation of mastoid obliteration surgery. Am J Otol. 1995 Jan;16(1):99-103.

25. Ridenour JS, Poe DS, Roberson DW. Complications with hydroxyapatite cement in mastoid cavity obliteration. Otolaryngol Head Neck Surg. 2008 Nov;139(5):641-5.

26. Cody DT, McDonald TJ. Mastoidectomy for acquired cholesteatoma: follow-up to 20 years. Laryngoscope. 1984 Aug;94(8):1027-30.

27. Austin DF. Staging in cholesteatoma surgery. J Laryngol Otol. 1989 Feb;103(2):143-8.

28. Aarts MC, Rovers MM, van der Veen EL, Schilder AG, van der Heijden GJ, Grolman W. The diagnostic value of diffusion-weighted magnetic resonance imaging in detecting a residual cholesteatoma. Otolaryngol Head Neck Surg. 2010 Jul;143(1):12-6. 